\title{
Numerical Investigation of Flapwise-Torsional Vibration Model of a Smart Section Blade with Microtab
}

\author{
Nailu Li, ${ }^{1}$ Mark J. Balas, ${ }^{2}$ Hua Yang, ${ }^{1}$ Wei Jiang, ${ }^{1}$ and Kaman T. Magar ${ }^{3}$ \\ ${ }^{1}$ School of Hydraulic, Energy and Power Engineering, Yangzhou University, Yangzhou, Jiangsu 225127, China \\ ${ }^{2}$ Aerospace Engineering, Embry-Riddle Aeronautical University, Daytona Beach, FL 32114-3900, USA \\ ${ }^{3}$ Wright State Research Institute, AFRL RQVC, Beavercreek, OH 45431, USA \\ Correspondence should be addressed to Nailu Li; nellylee85101@163.com
}

Received 16 April 2015; Revised 19 July 2015; Accepted 27 July 2015

Academic Editor: Peng Chen

Copyright (c) 2015 Nailu Li et al. This is an open access article distributed under the Creative Commons Attribution License, which permits unrestricted use, distribution, and reproduction in any medium, provided the original work is properly cited.

\begin{abstract}
This study presents a method to develop an aeroelastic model of a smart section blade equipped with microtab. The model is suitable for potential passive vibration control study of the blade section in classic flutter. Equations of the model are described by the nondimensional flapwise and torsional vibration modes coupled with the aerodynamic model based on the Theodorsen theory and aerodynamic effects of the microtab based on the wind tunnel experimental data. The aeroelastic model is validated using numerical data available in the literature and then utilized to analyze the microtab control capability on flutter instability case and divergence instability case. The effectiveness of the microtab is investigated with the scenarios of different output controllers and actuation deployments for both instability cases. The numerical results show that the microtab can effectively suppress both vibration modes with the appropriate choice of the output feedback controller.
\end{abstract}

\section{Introduction}

Blade vibration becomes one of the primary concerns as the increased-size blade leads to more flexible and long blades maintaining stiffness and minimizing mass. Due to the aerodynamic effects combined with the blade structural movement, the flutter happens when the wind speed reaches the decreased flutter speed due to increasing structural flexibility of the large blade (e.g., $50 \mathrm{~m}$ blades and above) [1]. The typical two degrees of freedom (DOE) of the blade caused by flutter involve torsion (torsional mode) and translation (flapwise mode). There are several factors that can affect the blade flutter instability, such as the centre of mass relative to the centre of the elastic axis in the blade sections, and the ratio between the torsional frequency and the flapwise frequency $[2,3]$. The classic flutter of the blade section occurs when the wind speed reaches the flutter speed, leading to the unstable oscillations (flutter instability). With increasing wind velocity, large amplitude of vibration without damping (divergence instability) can happen suddenly. Those flutters will greatly decrease the life of the blade without control. Therefore, there is an increasing interest in the flutter suppression via the smart blade, which is the blade equipped with the appropriate actuator, such as trailingedge flap and microtabs [4]. The trailing-edge flap has been widely used as the control surface to reject the load and control the aeroelastic instability of the blade [5-7]. For the recent decades, microtabs, proposed by Yen et al. [8], attract attention as an aerodynamic-effective, cost-efficient, quickactuation, and light-weight control surface.

The potential of the microtab to regulate blade loads has been numerically and experimentally studied by numerous researchers. Van Dam et al. [9] first proved the effectiveness of the microtab for load control numerically. Baek et al. [10] compared the load rejection effect of microtabs with that of flaps via proportional controller. The microtabs were also demonstrated as effective load controlling devices responding to a steady state aerodynamic model [11, 12]. Nakafuji et al. [13] presented microtab design and wind tunnel tests to verify the use of microtabs for active load control. Maughmer and Bramesfeld [14] carried out experimental investigation of fixed deployment of microtab as gurney flap. They found that 
a deployment of the microtab from lower surface increased the amount of lift while the deployment on the upper surface acted in the opposite way. Standish [15] computed complicated computational studies of tab height and tab location on the pressure side and suction side of the $\$ 809$ airfoil with the behavior as gurney flap, which is simply a short flat plate attached to the trailing-edge perpendicular to the chord line on the pressure or suction side of the airfoil. He then extended the work to rotorcraft applications [16]. However, most of those works mainly focused on microtab in flow field or microtabs as active aerodynamic load controller. The microtab effect on the passive flutter suppression of the blade has not generally been investigated.

For the purpose of microtab control analysis, a suitable, accurate, and computational-efficient aeroelastic model is needed. For classic flutter study, Theodorsen's theory has been widely used in modeling the two-dimensional incompressible flow for both fixed wing and rotating wing $[17,18]$. Later, for the purpose of analyzing the aeroelasticity using timemarching solution techniques, the aerodynamic behavior of the blade section has been modified in state-space form in time-domain. Different approximations to the Theodorsen theory also have been developed [19], and Van der Wall and Leishman concluded that, for moderate reduced frequencies, those theories give the same results as the Theodorsen theory. In this paper, one of the approximations is used to provide the aerodynamic model in time-domain for analysis in timedomain instead of frequency domain.

Moreover, the mathematical equations of the blade motions and the consequent computation of the solution are usually complicated and computationally expensive [2022]. However, for classic flutter of the blade, several studies showed that the dominating coupling of the structural modes with the aerodynamic forces is torsional mode and flapwise mode, and there is rarely coupling of the edgewise mode [23-25]. Therefore, the edgewise mode can be neglected to obtain a more efficient aeroelastic model. Although the blade motions and aerodynamic forces on the blade section have been studied, the aeroelastic model of a smart blade section with the coupling of blade motion, aerodynamic load, and microtab effect has not yet been investigated generally.

This paper demonstrates how the microtab actuator installed on the trailing-edge can affect the aeroelastic stability of the smart blade section in classic flutter. The contribution for this type of model is twofold: (1) it is a computational-efficient aeroelastic model that involves the interaction between aerodynamic forces, structural motion, and microtab actuation for the smart section blade study; (2) the model with the microtabs can be used to evaluate the potential sensors and control strategies for passive vibration control of the blade. The objective of this paper is to gain insight into the control capability of the microtabs on the aeroelasticity of the smart section blade, without complex high degree of freedom modeling or detailed computationalfluid-dynamics modeling. More importantly, this paper offers the preliminary results to design the advanced control algorithms for passive smart blade vibration control. The following sections present the structural model of the smart blade section, describe aerodynamic model applied to

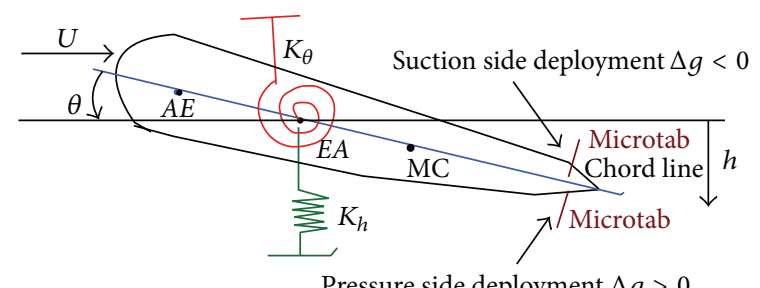

Figure 1: Model of the blade section with trailing-edge microtabs.

the smart section blade, summarize the state-space equations of the aeroelastic model, and analyze the passive control effect of the microtabs on two cases of aeroelastic instability with different choice of control inputs.

\section{Structural Model}

In this study, the smart blade section with the microtab actuator is modeled based on aerodynamic characteristics of the airfoil UA97W300 and the microtabs installed on the trailing-edge of the blade ( $90 \%$ chord). The smart blade section is shown in Figure 1.

Considering the two-degree-of-freedom (DOE) blade section model with structural linearity and aerodynamic nonlinearity, the differential equations of blade motions of flapwise-torsional oscillations can be written as [26]

$$
\begin{aligned}
& m \ddot{h}+m x_{\theta} b \ddot{\theta}+C_{h} \dot{h}+K_{h} h=-L_{E A}, \\
& m x_{\theta} b \ddot{h}+I_{\theta} \ddot{\theta}+C_{\theta} \dot{\theta}+K_{\theta} \theta=M_{E A},
\end{aligned}
$$

where $m$ is the mass, $h$ is the flapwise deflection, $\theta$ is the torsional deflection, $x_{\theta}$ is the dimensionless static unbalance about the elastic axis, $b$ is the semichord, $C_{h}, C_{\theta}$ are the flapwise and torsional damping coefficients, $I_{\theta}$ is the mass moment of inertia about the elastic axis, and $K_{h}, K_{\theta}$ are the flapwise and torsional stiffness coefficient. $L_{E A}$ and $M_{E A}$ are the generalized force and moment acting on the blade section.

The physical generalized forces and moments involve aerodynamic force/moment on the blade, the aerodynamic effects of the microtab actuation, and the supplemental terms regarding the asymmetry of the airfoil. The aerodynamic force and moment are caused by the aerodynamic loads that vary periodically as the blade rotates with constant rotor speed. The microtabs can affect the aerodynamic lift/moment acting on the blade by the deployment on the pressure side or the suction side of the blade with the height $g$ (Gurney flap). As illustrated in Figure 1, $\Delta g>0$ presents the microtab deployment on the pressure side and $\Delta g<0$ indicates the deployment on the suction side. The additional terms describe the static aerodynamic force and moment of the blade when the angle of attack is zero. Since the testing airfoil UA97W300 is an asymmetrical airfoil, the extra terms have 
nonzero coefficients when symmetric airfoil leads to no extra terms. The generalized force and moment can be expressed as

$$
\begin{aligned}
L_{E A}= & \frac{1}{2} \rho U^{2}(2 b) C_{L, \text { aero }}+\rho U^{2} b C_{L, \beta} g+\rho U^{2} b C_{L, \alpha_{0}}, \\
M_{E A}= & \frac{1}{2} \rho U^{2}(2 b)^{2} C_{M, \text { aero }}+2 \rho U^{2} b^{2} C_{M, \beta} g \\
& +2 \rho U^{2} b^{2} C_{M, \alpha_{0}},
\end{aligned}
$$

where $\rho$ is air density, $C_{L \text {,aero }}, C_{M \text {,aero }}$ are lift and moment coefficients with respect to aerodynamic loads, $C_{L, \beta}, C_{M, \beta}$ are lift and moment coefficients for microtab deployment, and $C_{L, \alpha_{0}}, C_{M, \alpha_{0}}$ are lift and moment coefficients at zero angle of attack for the airfoil. The apparent wind speed is $U$.

Define $\omega_{h}=\sqrt{K_{h} / m}, \omega_{\theta}=\sqrt{K_{\theta} / I_{\theta}}, \xi_{h}=C_{h} / 2 \omega_{h} m$, $\xi_{\theta}=C_{\theta} / 2 \omega_{\theta} I_{\theta}, \mu=m / \pi \rho b^{2}$, and $r_{\theta}=\sqrt{I_{\theta} / m b^{2}}$, where $\omega_{h}$, $\omega_{\theta}$ are uncoupled flapwise and torsional natural frequencies and $\xi_{h}, \xi_{\theta}$ are the critical damping factors in bending and torsion. Define the dimensionless quantities as $\bar{h}=h / b, U^{*}=$ $U / \omega_{\theta} b$, and $\bar{\omega}=\omega_{h} / \omega_{\theta}$, where $U^{*}$ is the dimensionless wind velocity, $\bar{h}$ is the dimensionless flapwise deflection, and $\bar{\omega}$ is the ratio between flapwise and torsional natural frequencies. The dimensionless motions of the equations of (1) can be rewritten as

$$
\begin{gathered}
\ddot{\bar{h}}+x_{\theta} \ddot{\theta}+2 \xi_{h}\left(\frac{M}{U^{*}} \bar{\omega}\right) \dot{\bar{h}}+\left(\frac{M}{U^{*}} \bar{\omega}\right)^{2} \bar{h}=-l_{E A}, \\
x_{\theta} \ddot{\bar{h}}+r_{\theta}^{2} \ddot{\theta}+2 \xi_{\theta} r_{\theta}^{2} \frac{M}{U^{*}} \dot{\theta}+r_{\theta}^{2}\left(\frac{M}{U^{*}}\right)^{2} \theta=m_{E A},
\end{gathered}
$$

where

$$
\begin{aligned}
l_{E A} & =\frac{M^{2}}{\mu \pi}\left(C_{L, \text { aero }}+C_{L, \beta} g+C_{L, \alpha_{0}}\right), \\
m_{E A} & =\frac{2 M^{2}}{\mu \pi}\left(C_{M, \text { aero }}+C_{M, \beta} g+C_{M, \alpha_{0}}\right),
\end{aligned}
$$

where $r_{\theta}$ is the dimensionless radius of gyration with respect to elastic axis, $M$ is the Mach number, and $\mu$ is the dimensionless mass. The $C_{L, \alpha_{0}}, C_{M, \alpha_{0}}$ can be computed using experimental static data of the airfoil at zero angle of attack. $C_{L, \beta}, C_{M, \beta}$ are derived from curve fittings of lift force/moment data with respect to gurney flap (the deployment of the microtab) from wind tunnel test. $C_{L \text {,aero }}, C_{M \text {,aero }}$ are aerodynamic lift/moment that can be obtained from aerodynamic model.

Let the state variables for the dimensionless structural model be $\bar{h}=z_{1}, \theta=z_{2}, \dot{\bar{h}}=z_{3}, \dot{\theta}=z_{4}$, and $z=$ $\left[\begin{array}{llll}z_{1} & z_{2} & z_{3} & z_{4}\end{array}\right]^{T} ;(3)$ can be rewritten as

$$
\begin{aligned}
\dot{z}= & {\left[\begin{array}{cc}
0 & I \\
-M_{0}^{-1} K_{0} & -M_{0}^{-1} D_{0}
\end{array}\right] z+\left[\begin{array}{c}
0 \\
M_{0}^{-1} C_{0}
\end{array}\right]\left[\begin{array}{c}
C_{L, \text { aero }} \\
C_{M, \text { aero }}
\end{array}\right] } \\
& +\left[\begin{array}{c}
0 \\
M_{0}^{-1} C_{0}
\end{array}\right]\left[\begin{array}{c}
C_{L, g} \\
C_{M, g}
\end{array}\right] g+\left[\begin{array}{c}
0 \\
M_{0}^{-1} C_{0}
\end{array}\right]\left[\begin{array}{c}
C_{L, \alpha_{0}} \\
C_{M, \alpha_{0}}
\end{array}\right],
\end{aligned}
$$

where

$$
\begin{aligned}
M_{0} & =\left[\begin{array}{cc}
1 & x_{\theta} \\
x_{\theta} & r_{\theta}^{2}
\end{array}\right], \\
D_{0} & =\left[\begin{array}{cc}
2 \xi_{h}\left(\frac{M}{U^{*}} \bar{\omega}\right) & 0 \\
0 & 2 \xi_{\theta} r_{\theta}^{2} \frac{M}{U^{*}}
\end{array}\right], \\
K_{0} & =\left[\begin{array}{cc}
\left(\frac{M}{U^{*}} \bar{\omega}\right)^{2} & 0 \\
0 & r_{\theta}^{2}\left(\frac{M}{U^{*}}\right)^{2}
\end{array}\right], \\
C_{0} & =\left[\begin{array}{cc}
-\frac{M^{2}}{\mu \pi} & 0 \\
0 & \frac{2 M^{2}}{\mu \pi}
\end{array}\right] .
\end{aligned}
$$

Define the control input $u=g, y_{a}=\left[\begin{array}{lll}C_{L \text {,aero }} & C_{M \text {,aero }}\end{array}\right]^{T}$; the state-space equations of the blade model with microtab actuator in (5) can be expressed as

$$
\dot{z}=A_{s} z+B_{s} y_{a}+B_{g} g+B_{0}
$$

where

$A_{s}$

$$
=\left[\begin{array}{cccc}
0 & 0 & 1 & 0 \\
0 & 0 & 0 & 1 \\
\frac{-\left(M \bar{\omega} r_{\theta}\right)^{2}}{U^{* 2}\left(r_{\theta}^{2}-x_{\theta}^{2}\right)} & \frac{x_{\theta}\left(M r_{\theta}\right)^{2}}{U^{2}\left(r_{\theta}^{2}-x_{\theta}^{2}\right)} & \frac{-2 \xi_{h} M \bar{\omega} r_{\theta}^{2}}{U^{*}\left(r_{\theta}^{2}-x_{\theta}^{2}\right)} & \frac{2 \xi_{\theta} M x_{\theta} r_{\theta}^{2}}{U^{*}\left(r_{\theta}^{2}-x_{\theta}^{2}\right)} \\
\frac{x_{\theta}(M \bar{\omega})^{2}}{U^{* 2}\left(r_{\theta}^{2}-x_{\theta}^{2}\right)} & \frac{-\left(M r_{\theta}\right)^{2}}{U^{* 2}\left(r_{\theta}^{2}-x_{\theta}^{2}\right)} & \frac{2 \xi_{h} M \bar{\omega} x_{\theta}}{U^{*}\left(r_{\theta}^{2}-x_{\theta}^{2}\right)} & \frac{-2 \xi_{\theta} M r_{\theta}^{2}}{U^{*}\left(r_{\theta}^{2}-x_{\theta}^{2}\right)}
\end{array}\right]
$$$$
B_{s}=\left[\begin{array}{cc}
0 & 0 \\
0 & 0 \\
\frac{-\left(M r_{\theta}\right)^{2}}{\mu \pi\left(r_{\theta}^{2}-x_{\theta}^{2}\right)} & \frac{-2 M^{2} x_{\theta}}{\mu \pi\left(r_{\theta}^{2}-x_{\theta}^{2}\right)} \\
\frac{M^{2} x_{\theta}}{\mu \pi\left(r_{\theta}^{2}-x_{\theta}^{2}\right)} & \frac{2 M^{2}}{\mu \pi\left(r_{\theta}^{2}-x_{\theta}^{2}\right)}
\end{array}\right] \text {, }
$$

$$
\begin{aligned}
& B_{g}=\left[\begin{array}{c}
0 \\
0 \\
\frac{-M^{2}\left(r_{\theta}^{2} C_{L, g}+2 x_{\theta} C_{M, g}\right)}{\mu \pi\left(r_{\theta}^{2}-x_{\theta}^{2}\right)} \\
\frac{M^{2}\left(x_{\theta} C_{L, g}+2 C_{M, g}\right)}{\mu \pi\left(r_{\theta}^{2}-x_{\theta}^{2}\right)}
\end{array}\right], \\
& B_{0}=B_{s}\left[\begin{array}{c}
C_{L, \alpha_{0}} \\
C_{M, \alpha_{0}}
\end{array}\right] .
\end{aligned}
$$

\section{Aerodynamic Model}

3.1. Aerodynamic Model Based on the Theodorsen Theory. In this study, the aeroelastic stability is affected by the aerodynamic force in linear region for classic flutter research. An aerodynamic model approximated to the Theodorsen 
theory [17] is used to compute the unsteady aerodynamic force for classic vibration of two-dimensional airfoil in the attached flow. Taking into account Theodorsen theory, the unsteady lift on the blade section is given as [25]

$$
\begin{aligned}
L= & \pi \rho \frac{c^{2}}{4}(U \dot{\alpha}+\ddot{h}) \\
& +\pi \rho c U\left(\omega_{3 / 4}(0) \phi(s)+\int_{0}^{s} \frac{d \omega_{3 / 4}}{d \sigma} \phi(s-\sigma) d \sigma\right),
\end{aligned}
$$

where $U$ is the apparent wind speed, $c$ is the chord length, $\alpha$ is the geometric angle of attack between chord and freestream flow, and $\omega_{3 / 4}$ is the downwash at the three-quarter point, related to the motions of the blade section. $\phi$ is an indicial function and $s$ is the dimensionless time-scale. The unsteady lift is a combination of noncirculatory part due to the acceleration of the air mass and the circulatory part with Duhamel's integral for the memory effect of previously shed vorticity.

$\phi$ can be approximated as

$$
\phi(s)=1-A_{1} e^{-b_{1} s}-A_{2} e^{-b_{2} s},
$$

where $A_{1}, A_{2}, b_{1}$, and $b_{2}$ are constant, indicating two time lags.

$s$ is described as

$$
s=\frac{2}{c} \int_{t^{\prime}}^{t} U(\tau) d \tau
$$

Then, the effective downwash at the three-quarter point can be expressed as

$$
\begin{aligned}
\omega_{3 / 4}^{\mathrm{eff}}= & \omega_{3 / 4}(t) \phi(0) \\
& -\int_{0}^{t} \omega_{3 / 4}\left(t^{\prime}\right) \frac{d \phi}{d t^{\prime}}\left(\frac{2}{c} \int_{t^{\prime}}^{t} U(\tau) d \tau\right) d t^{\prime} .
\end{aligned}
$$

Substituting (10) and (11) into (12) gives

$$
\omega_{3 / 4}^{\mathrm{eff}}=\omega_{3 / 4}(t)\left(1-A_{1}-A_{2}\right)+x_{1}(t)+x_{2}(t),
$$

where the state variables $x_{i}(t)$ can be written as

$$
x_{i}(t)=\frac{2}{c U} b_{i} A_{i} \int_{0}^{t} \omega_{3 / 4}\left(t^{\prime}\right) U\left(t^{\prime}\right) e^{-(2 / c) b_{i} \int_{t^{\prime}}^{t} U(\tau) d \tau} d t^{\prime},
$$

where $i=1,2$. And $x_{i}(t)$ is the solution to the differential equations as

$$
\dot{x}_{i}+\frac{2 U}{c} b_{i} x_{i}=b_{i} A_{i} \frac{2 U}{c} \alpha_{3 / 4},
$$

where the angle of attack at three-quarter $\alpha_{3 / 4}=\omega_{3 / 4} / U$. Although the equation is linear in aerodynamic state variables $x_{i}(t)$, the structural states are coupled nonlinearly with $x_{i}(t)$ through $U$ and $\alpha_{3 / 4}$. This equation describes the effective downwash determining the dynamics of unsteady lift coefficient for attached flow.
With the aerodynamic state variables $x_{1}(t), x_{2}(t)$, the effect angle of attack can be written as

$$
\alpha_{E}=\alpha_{3 / 4}\left(1-A_{1}-A_{2}\right)+x_{1}(t)+x_{2}(t) .
$$

The unsteady lift for attached flow can be rewritten as

$$
C_{L}^{P}=2 \pi\left(\alpha_{E}-\alpha_{0}\right)+\frac{\pi c \dot{\theta}}{2 U}
$$

where $\alpha_{0}$ is the angle of attack at zero lift.

Let $T_{u}=c / 2 U$; the dynamic lift coefficient $C_{L \text {,aero }}$ in (7) can be written as

$$
C_{L, \text { aero }}=C_{L, \alpha}\left(\alpha_{E}-\alpha_{0}\right)+\pi T_{u} \dot{\theta}
$$

where the first term represents the dynamics of the attached flow, the second term describes the dynamics of the separated flow, and the last is the added mass term related to the rate of torsional deflection.

The equivalent pressure center can be obtained by the static lift and moment coefficients as

$$
a^{\text {st }}=\frac{\left(C_{M}^{\text {st }}-C_{M_{0}}\right)}{C_{L}^{\text {st }}} .
$$

The dynamic moment coefficient $C_{M \text {,aero }}$ in (7) can be written as

$$
C_{M, \text { aero }}=C_{M}^{\mathrm{st}}\left(\alpha_{E}\right)-\frac{\pi c \dot{\theta}}{4 U},
$$

where $C_{M}^{\mathrm{st}}$ is the static moment coefficient, and the other term is the added mass term related to the rate of torsional deflection.

3.2. Linearization of the Nonlinear Aerodynamic Model. For the purpose of stability analysis and control design, the nonlinear aerodynamic model in (15), (18), and (20) needs to be linearized. Assume the small perturbations about the equilibrium as

$$
\begin{aligned}
x_{i}(t) & =x_{i}^{0}+\epsilon x_{i}^{1}(t), \quad i=1,2,3,4, \\
\alpha(t) & =\alpha^{0}+\epsilon \alpha^{1}(t), \\
\alpha_{3 / 4}(t) & =\alpha^{0}+\epsilon \alpha_{3 / 4}^{1}(t),
\end{aligned}
$$

where $x_{i}^{1}(t)$ is the small perturbation of the dynamic state variables, $\epsilon$ is far more less than one, $x_{i}^{0}$ is the steady state of the variables, and $\alpha^{0}$ is the steady angle of attack.

Substituting (27), (28) into (15), (20), and (22) gives the steady states of the equations as

$$
\begin{aligned}
& x_{1}^{0}=A_{1} \alpha^{0}, \\
& x_{2}^{0}=A_{2} \alpha^{0}
\end{aligned}
$$

with the $\epsilon^{1}$-order equations as

$$
\begin{aligned}
& \dot{x}_{1}^{1}+T_{1}^{-1} x_{1}^{1}=T_{1}^{-1} A_{1} \alpha_{3 / 4}^{1}(t), \\
& \dot{x}_{2}^{1}+T_{2}^{-1} x_{2}^{1}=T_{2}^{-1} A_{2} \alpha_{3 / 4}^{1}(t),
\end{aligned}
$$


where the time constant $T_{1}=c / 2 U_{0} b_{1}, T_{2}=c / 2 U_{0} b_{2}$, with $U(t)=U_{0}+\epsilon U_{1}(t)$. Consequently, the nonlinear unsteady lift/moment coefficients in (23), (26) are linearized as

$$
\begin{aligned}
C_{L, \text { aero }}^{\mathrm{Lin}} & =C_{L}^{0}+c_{l, \alpha} \alpha_{E}^{1}+\pi T_{0} \dot{\alpha}^{1}(t), \\
C_{M, \text { aero }}^{\mathrm{Lin}} & =C_{M}^{0}+c_{m, \alpha} \alpha_{E}^{1}-\frac{\pi}{2} T_{0} \dot{\alpha}^{1}(t),
\end{aligned}
$$

where $C_{L}^{0}, C_{M}^{0}$ are static lift and moment coefficients at the steady state angle of attack. $c_{l, \alpha}, c_{m, \alpha}$ are Taylor expansion coefficients with respect to effective angle of attack and separate point separately in (31) and are given as

$$
\begin{gathered}
c_{l, \alpha}=C_{L, \alpha} f_{0}+\left.\frac{d C_{L}^{f s}}{d \alpha}\right|_{\alpha=\alpha^{0}}\left(1-f_{0}\right), \\
c_{m, \alpha}=\left.\frac{d C_{M}^{\text {st }}}{d \alpha}\right|_{\alpha=\alpha^{0}}-\left.\left.C_{L}^{0} \frac{d f^{s t}}{d \alpha}\right|_{\alpha=\alpha^{0}} \frac{d a^{s t}}{d f}\right|_{\alpha=\alpha^{0}} .
\end{gathered}
$$

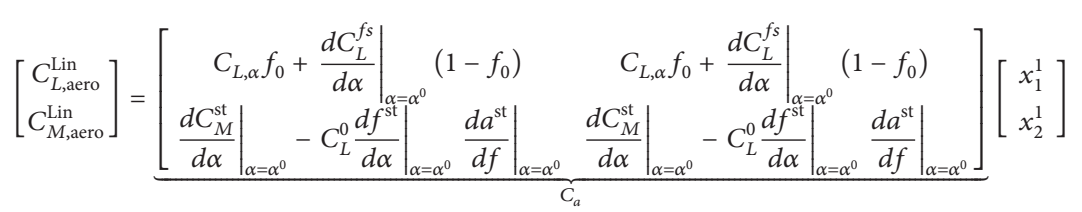

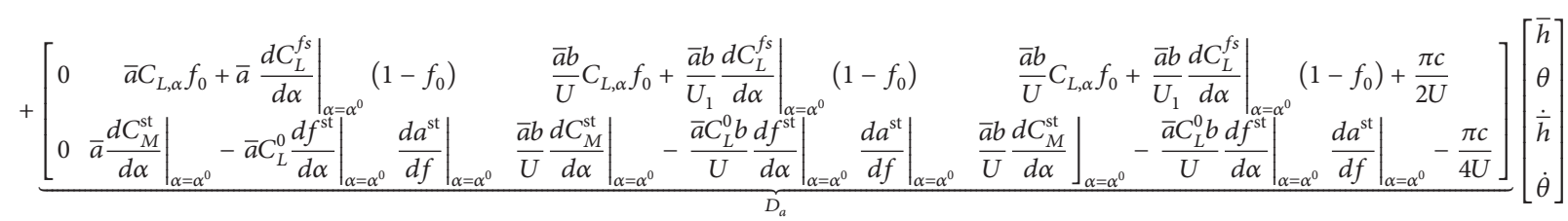

$$
\begin{aligned}
& +\left[\begin{array}{c}
C_{L}^{0} \\
C_{M}^{0}
\end{array}\right] .
\end{aligned}
$$

The state-space equations of the dynamic lift and moment coefficients in (25), (26) can be written as
Let $\alpha_{3 / 4}^{1}(t)=\left(b \dot{\bar{h}}^{1} / U\right)+\theta^{1}+\left(b \dot{\theta}^{1} / U\right), \bar{a}=1-A_{1}-A_{2}$, and define the state variables of the aerodynamic model, $x=\left[\begin{array}{ll}x_{1}^{1} & x_{2}^{1}\end{array}\right]^{T}$. The state-space equations of the aerodynamic model in (30) are written as

$$
\left[\begin{array}{l}
\dot{x}_{1}^{1} \\
\dot{x}_{2}^{1}
\end{array}\right]=\underbrace{\left[\begin{array}{cc}
-T_{1}^{-1} & 0 \\
0 & -T_{2}^{-1}
\end{array}\right]}_{A_{a}}\left[\begin{array}{l}
x_{1}^{1} \\
x_{2}^{1}
\end{array}\right]
$$$$
+\underbrace{\left[\begin{array}{cccc}
0 & T_{1}^{-1} A_{1} & \frac{T_{1}^{-1} A_{1} b}{U} & \frac{T_{1}^{-1} A_{1} b}{U} \\
0 & T_{2}^{-1} A_{2} & \frac{T_{2}^{-1} A_{2} b}{U} & \frac{T_{2}^{-1} A_{2} b}{U} \\
0 & \bar{a} T_{p}^{-1} C_{L, \alpha} & \frac{\bar{a} b T_{p}^{-1} C_{L, \alpha}}{U} & \frac{\bar{a} b T_{p}^{-1} C_{L, \alpha}}{U_{0}}+\frac{\pi T_{P}^{-1} b}{U} \\
0 & 0 & 0
\end{array}\right]}_{B_{a}}\left[\begin{array}{c}
\bar{h} \\
\theta \\
\bar{h} \\
\dot{\theta}
\end{array}\right] .
$$ 


$$
\begin{aligned}
& +\left[\begin{array}{c}
0 \\
0 \\
\frac{r_{\theta}^{2}\left(C_{L, \alpha_{0}}+C_{L}^{0}\right)-x_{\theta}\left(C_{M, \alpha_{0}}+C_{M}^{0}\right)}{r_{\theta}^{2}-x_{\theta}^{2}} \\
\frac{\left(C_{M, \alpha_{0}}+C_{M}^{0}\right)-x_{\theta}\left(C_{L, \alpha_{0}}+C_{L}^{0}\right)}{r_{\theta}^{2}-x_{\theta}^{2}} \\
0 \\
0
\end{array}\right], \\
& y=\left[\begin{array}{llllll}
c_{1} & c_{2} & c_{3} & c_{4} & 0 & 0
\end{array}\right]\left[\begin{array}{c}
\bar{h} \\
\theta \\
\dot{\bar{h}} \\
\dot{\theta} \\
x_{1}^{1} \\
x_{2}^{1}
\end{array}\right] .
\end{aligned}
$$

\section{Aeroelastic Analysis}

In order to investigate the aeroelastic stability of the system and the effect of the microtab on vibration suppression of the system, the following model parameters are used as [20]: $m=50 \mathrm{~kg}, K_{h}=2884 \mathrm{~N} / \mathrm{m}, C_{h}=7.54 \mathrm{~kg} / \mathrm{s}$, $K_{\theta}=700, C_{\theta}=0.23 \mathrm{kgm}^{2} / \mathrm{s}, I_{\theta}=0.4 \mathrm{~m}^{2} \mathrm{~kg}, \rho=$ $1.2 \mathrm{~kg} / \mathrm{m}^{3}$, and $b=0.5 \mathrm{~m}$. For these parameters, the flapwise vibration mode and the torsional vibration mode have the undamped natural frequencies of $6.28 \mathrm{rad} / \mathrm{s}(1 \mathrm{~Hz})$ and $50.24 \mathrm{rad} / \mathrm{s}(8 \mathrm{~Hz})$, which are compared to the values of $1.1 \mathrm{~Hz}$ and $8 \mathrm{~Hz}$ modal natural frequencies in [20] for flapwise and torsional deflection separately. The $C_{L, \beta}, C_{M, \beta}$ are computed by numerical simulation with commercial CFD code in FLUENT 6.3 software based on Reynolds-averaged NavierStokes equations based on wind tunnel experimental data. Those lift/moment coefficients are taken for nondimensional gurney flap for microtab deployment.

The equations of motions for the aeroelastic model in (31) can be rewritten as the following form:

$$
\begin{aligned}
\dot{q} & =\left[\begin{array}{c}
\dot{z} \\
\dot{x}
\end{array}\right] \\
& =\underbrace{\left[\begin{array}{cc}
A_{s}+B_{s} D_{a} & B_{s} C_{a} \\
B_{a} & A_{a}
\end{array}\right]}_{A}\left[\begin{array}{c}
z \\
x
\end{array}\right]+\underbrace{\left[\begin{array}{c}
B_{g} \\
0
\end{array}\right]}_{B} g+\left[\begin{array}{c}
B_{0} \\
0
\end{array}\right], \\
y & =\underbrace{\left[\begin{array}{ll}
C_{s} & 0
\end{array}\right]}_{C}\left[\begin{array}{c}
z \\
x
\end{array}\right],
\end{aligned}
$$

where $A_{s}, B_{s}$, and $C_{s}$ are derived from structural model, $A_{a}$, $B_{a}, C_{a}$, and $D_{a}$ are derived from aerodynamic model, $B_{q}$ is the control input matrix, related to the actuation of the microtab, and $B_{0}$ is constant matrix. It can be seen that the system state matrix $A$ has structural components that are coupled with aerodynamic components. The system input matrix $B$ and output matrix $C$ only have structural components. The aerodynamic force influence on the stability of the blade section is analyzed by looking at the eigenvalues of the aeroelastic system in (32). The complex conjugate eigenvalues with positive real part indicate flutter instability, and the eigenvalues with only positive real part reveal divergence instability. The specific frequency and the damp ratio of the damping mode can be computed by the eigenvalues. Before the aeroelastic stability and control analysis is studied, the established model needs to be validated.

4.1. Model Validation by Comparison of the Results with the Study of Kallesøe [20]. The vibration modes of classic flutter for the blade section have been investigated by Kallesøe. In his study, the numerical results were given for the blade with flapwise, edgewise, and torsional motions at the low angle of attack $\alpha=2^{\circ}$ for classic flutter study. The edgewise mode was indicated to have very small coupling with the aerodynamic forces, and the combined torsional and flapwise motion is primarily responsible for the instability, known as classic flutter. The flutter mode changes from well damped (flutter instability) to highly unstable (divergence instability) within a relatively small increase in air speed.

The flapwise mode and torsional mode are also carried out in this study in Section 2. When the apparent wind velocity does not reach the flutter speed, the system is stable with the preflutter speed of $U=11 \mathrm{~m} / \mathrm{s}$. On this condition, the structural mode has the system matrix as

$$
A_{s}=\left[\begin{array}{cccc}
0 & 0 & 1 & 0 \\
0 & 0 & 0 & 1 \\
-0.0004 & 0.0012 & -0.0005 & 0.0002 \\
0.0012 & -0.0117 & 0.0015 & -0.0018
\end{array}\right] \text {. }
$$


TABLE 1: Eigenvalues for structural and aeroelastic models with $U=$ $11 \mathrm{~m} / \mathrm{s}$ and $\alpha=2^{\circ}$.

\begin{tabular}{lcc}
\hline & Present model & Kallesøe [20] \\
\hline Structural & $-0.0010 \pm 0.1087 i$ & $\omega_{\theta}=8 \mathrm{~Hz}$ \\
model & $\left.\omega_{\theta}=0.1087, \xi_{\theta}=0.92 \%\right)$ & $\xi_{\theta}=1 \%$ \\
& $-0.0002 \pm 0.0162 i$ & \\
& $\left(\omega_{h}=0.0162, \xi_{h}=1.2 \%\right)$ & $\omega_{h}=1.1 \mathrm{~Hz}$ \\
& $\omega_{h}=1 \mathrm{~Hz}$ & $\xi_{h}=1 \%$ \\
\hline Aeroelastic & $-0.002 \pm 0.1071 i$ & $\omega_{\theta}=7.9 \mathrm{~Hz}$ \\
model & $\left(\omega_{\theta}=0.1071, \xi_{\theta}=1.8 \%\right)$ & $\xi_{\theta}=1.99 \%$ \\
& $\omega_{h}=7.95 \mathrm{~Hz}$ & \\
& $-0.004 \pm 0.0151 i$ & $\omega_{h}=1.1 \mathrm{~Hz}$ \\
& $\left(\omega_{h}=0.01515, \xi_{h}=0.26\right)$ & $\xi_{h}=0.29$ \\
\hline
\end{tabular}

With the angle of attack $\alpha=2^{\circ}$ and $U=11 \mathrm{~m} / \mathrm{s}$, the aeroelastic model has the system matrix as

A

$$
=\left[\begin{array}{cccccc}
0.000 & 0.0000 & 1.00000 & 0.0000 & 0.000 & 0.0000 \\
0.000 & 0.0000 & 0.00000 & 1.0000 & 0.000 & 0.0000 \\
-0.0004 & 0.0011 & -0.0005 & 0.0002 & -0.0001 & -0.0001 \\
0.0012 & -0.0114 & 0.0015 & -0.0023 & 0.00050 & 0.0005 \\
0.0000 & -1.0511 & 0.0075 & 0.0075 & -6.3700 & 0.0000 \\
0.0000 & -14.070 & 0.1005 & 0.1005 & 0.000 & -42.0000
\end{array}\right] .
$$

For the structural model, the homogenous part of equation of motion can be written as $\dot{z}=A_{s} z$, with the state vector $z=\left[\begin{array}{llll}\bar{h} & \theta & \dot{\bar{h}} & \dot{\theta}\end{array}\right]^{T}$; for the aeroelastic model, the homogenous part of equation of motion is $\dot{q}=A q$, with the state vector $q=\left[\begin{array}{ll}z^{T} & x^{T}\end{array}\right]^{T}$. The eigenvalues of two models are shown in Table 1. The structural model has two eigenvalues predominately related to torsional mode $(8.17 \mathrm{~Hz})$ and other two mainly associated with flapwise mode $(1 \mathrm{~Hz})$, all with small negative real part, corresponding to small structural damping $(0.92 \%, 1.2 \%)$. The computed nondimensional resonance frequencies $\left(\omega_{\theta}, \omega_{h}\right)$ can be converted back to resonance frequencies by $\omega_{\theta}=\omega_{\theta} U / M b$, $\omega_{h}=\Phi_{h} U / M b$. The aeroelastic model has four eigenvalues more than the structural model, representing four heavily damped aerodynamic states. The torsional mode is a little affected by the effect of aerodynamic force while flapwise mode has more negative real part compared with that in structural model, corresponding to larger flapwise damping. The results are consistent with the model for blade fatigue load control developed by Kallesøe, which showed the same system dynamic for the structural and aeroelastic models in Table 1.

4.2. Aeroelastic Analysis. There are mainly two kinds of unstable system response of the aeroelastic system. One is the flutter instability, which occurs when the apparent wind velocity reaches the flutter speed and the system begins to flutter with oscillations. The other one is the divergence instability when the system is unstable and heavily damped
TABLE 2: Eigenvectors of aeroelastic models with $U=16 \mathrm{~m} / \mathrm{s}$.

\begin{tabular}{lcccc}
\hline Eigenvalue & $0.01 \pm 0.04 i$ & $-0.0001 \pm 0.0065 i$ & -15.73 & -104.31 \\
\hline $\bar{h}$ & $-0.0951 \mp 0.0010 i$ & -0.9863 & 0.0032 & -0.0002 \\
\hline$\theta$ & 0.9318 & $-0.1102 \pm 0.1082 i$ & -0.0322 & 0.0020 \\
\hline$\dot{\bar{h}}$ & $-0.0007 \mp 0.0041 i$ & $0.0001 \mp 0.0064 i$ & -0.0507 & 0.0213 \\
\hline$\dot{\theta}$ & $0.0071 \pm 0.0402 i$ & $-0.0007 \mp 0.0007 i$ & 0.5066 & -0.2133 \\
\hline$x_{1}^{1}$ & $-0.1537 \pm 0.0004 i$ & $0.0182 \mp 0.0179 i$ & 0.8366 & 0.0001 \\
\hline$x_{2}^{1}$ & $-0.3121 \pm 0.0002 i$ & $0.0369 \mp 0.0363 i$ & 0.0132 & -0.8992 \\
\hline
\end{tabular}

TABLE 3: Eigenvectors of aeroelastic models with $U=24 \mathrm{~m} / \mathrm{s}$.

\begin{tabular}{lccccc}
\hline Eigenvalue & 7.96 & 0.0018 & $-0.01 \pm 0.64 i$ & -17.13 & -103.96 \\
\hline $\bar{h}$ & 0.0122 & -0.0007 & -0.9995 & -0.0051 & 0.0005 \\
\hline$\theta$ & -0.1223 & -0.9368 & $0.0281 \mp 0.0037 i$ & 0.0513 & -0.0046 \\
\hline$\dot{\bar{h}}$ & 0.0973 & -0.0000 & $0.0001 \mp 0.0064 i$ & 0.0878 & -0.0478 \\
\hline$\dot{\theta}$ & -0.9733 & -0.0002 & $0.0000 \pm 0.0002 i$ & -0.8785 & 0.4784 \\
\hline$x_{1}^{1}$ & 0.0132 & 0.1546 & $-0.0046 \pm 0.0006 i$ & 0.1417 & -0.0002 \\
\hline$x_{2}^{1}$ & 0.0373 & 0.3138 & $-0.0094 \pm 0.0012 i$ & -0.0214 & 0.0878 \\
\hline
\end{tabular}

with no oscillations. In this section, both of those two instability cases are investigated for the aeroelastic model.

4.2.1. Flutter Instability. The eigenvectors of the aeroelastic model at flutter speed $U=16 \mathrm{~m} / \mathrm{s}$ are shown at Table 2 . The eigenvectors associated with the unstable eigenvalues of $0.01 \pm$ $0.04 i$ and $-0.0001 \pm 0.0065 i$ reveal that the torsional mode is flutter instability with the imaginary parts and flapwise mode is largely drawn towards the imaginary axis by the inclusion of the aerodynamic forces. These results are reasonable based on the fact that the aerodynamic flow acts mainly in the attached flow region with the low angle of attack. The other two eigenvalues of -104.31 and -15.73 are mainly for the attached flow, which are also coupled with $\dot{\theta}$.

4.2.2. Divergence Instability. For $U=24 \mathrm{~m} / \mathrm{s}$, the eigenvectors of the aeroelastic model are given in Table 3. The divergence instability of torsional modes are shown by the eigenvalues of 7.96 and 0.0018 with no imaginary parts, and the corresponding eigenvectors also reveal the coupling of the mode and the attached flow. The eigenvectors of four aerodynamic eigenvalues indicate that, on the condition of divergence instability, the coupling of the aerodynamic force and structural model is even stronger than that on flutter instability condition.

\section{Control Analysis}

5.1. Control Strategies for Microtab Actuation. In order to implement the microtab actuation effectively for blade vibration control, the sensors need to be chosen carefully to design the controller. Here, four strategies of adopting sensors are investigated for microtab control on flutter instability and divergence instability cases separately. For appropriate output feedback gain $G_{e}$, the feedback aeroelastic system can be written as $\dot{q}=A q+B u$. The different output controllers are 

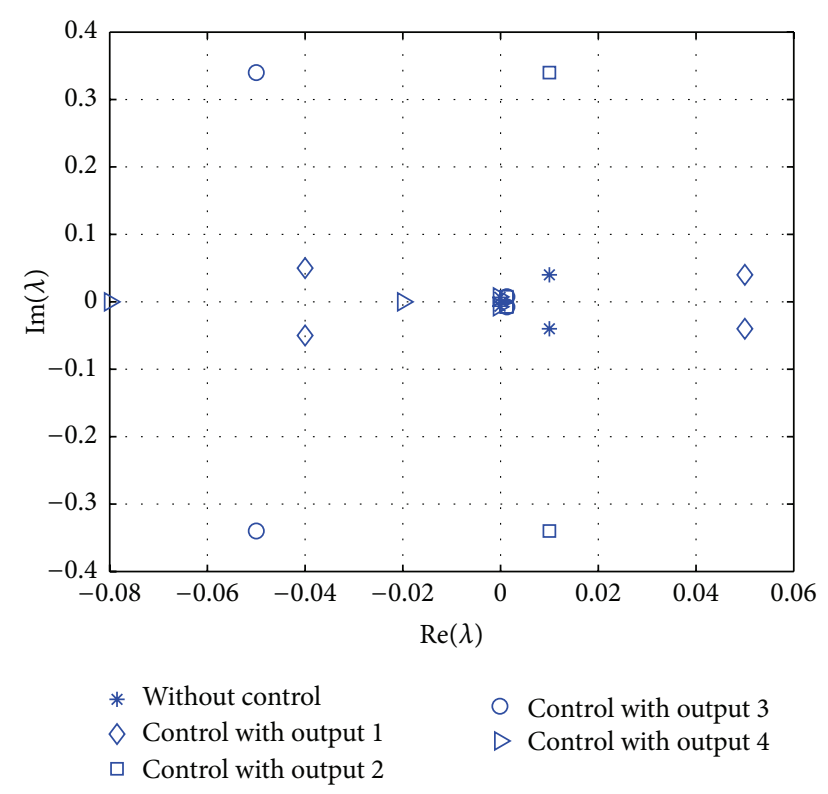

FIGURE 2: Eigenvalues $\lambda$ of the aeroelastic model with different output controllers for flutter instability case $(U=16 \mathrm{~m} / \mathrm{s})$.

$u=G_{e} y$ with the output 1 of $y=\bar{h}$, output 2 of $y=\theta$, output 3 of $y=\theta+\dot{\theta}$, and output 4 of $y=\dot{\theta}$. In practice, those output signals can be sensed by meter sensor of $h$, angular sensor of $\theta$, and rate gyro of $\dot{\theta}$. For the controllability and observability, since the output feedback controller is used for microtab, the output controllability criteria [27] are used to evaluate the controllability and observability of the outputs at the same time. The output controllability matrix is computed with the $(A, B, C)$ matrices in (32) and (33). For different output choice, the $C$ is taken as $C_{1}, C_{2}, C_{3}$, and $C_{4}$. The aeroelastic model with microtab and four outputs are $\left(A, B, C_{1}\right),\left(A, B, C_{2}\right),\left(A, B, C_{3}\right)$, and $\left(A, B, C_{4}\right)$ separately, and the corresponding output controllability matrices are all solved with the rank, which is equal to the row number of $C_{i}$, $(i=1,2,3,4)$, which satisfies the requirement of the criteria. Therefore, the aeroelastic model for microtab is completely output controllable.

5.1.1. Flutter Instability Case (Case 1). When the flutter instability occurs at $U=16 \mathrm{~m} / \mathrm{s}$, the eigenvalues of the feedback system with the same feedback gain $G_{e}=-2$ and four different output controllers are shown in Figure 2. The choice of output 2 has no effect on suppressing the vibration modes $(0.01 \pm 0.34 i, 0.0013 \pm 0.0076 i)$; output 1 and output 3 can control the torsional mode $(-0.04 \pm 0.05 i,-0.05 \pm 0.34 i)$ at the cost of losing the controllability of flapwise mode $(0.05 \pm 0.04 i$, $0.0013 \pm 0.0076 i)$; output 4 (derivative of torsional deflection) has the full controllability of both modes $(-0.0004 \pm 0.0073 i$, $-0.08,-0.02)$. It reveals that $\dot{\theta}$ is the most powerful sensor signal for microtab control on flutter instability case. The failure of output 3 shows the stronger impact of $\theta$ than that of $\dot{\theta}$ in the signal combination, and an adjustment of the weight of $\dot{\theta}$ in output 3 can retain the controllability.

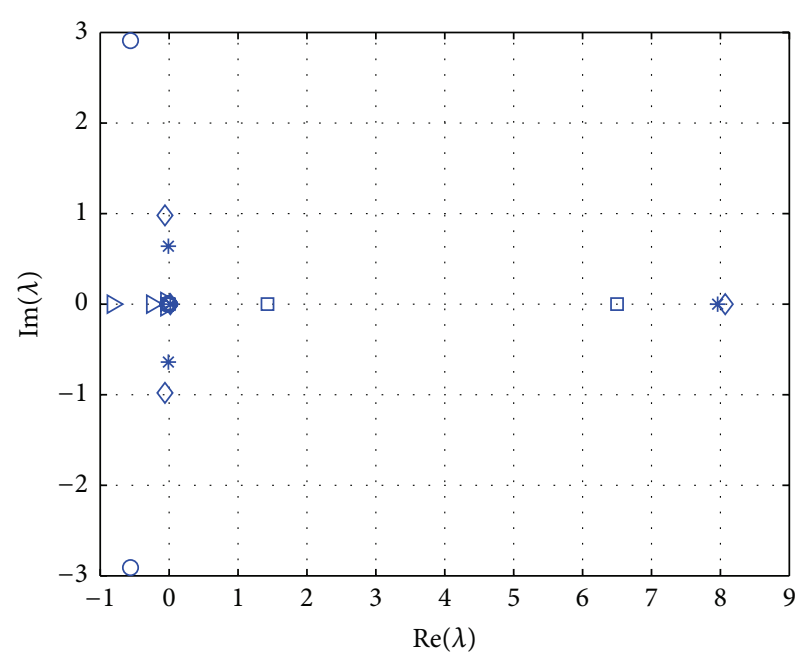

$\begin{array}{ll}* \text { Without control } & \bigcirc \text { Control with output } 3 \\ \diamond \text { Control with output 1 } & \triangleright \text { Control with output } 4 \\ \square \text { Control with output } 2 & \end{array}$

FIgURE 3: Eigenvalues $\lambda$ of the aeroelastic model with different output controllers for divergence instability case $(U=24 \mathrm{~m} / \mathrm{s})$.

5.1.2. Divergence Instability Case (Case 2). On the divergence instability condition of $U=24 \mathrm{~m} / \mathrm{s}$, the eigenvalues of the feedback system with four different sensor strategies and feedback gain $G_{e}=-200$ are shown in Figure 3. The aeroelastic stability has not been improved by microtab control associated with output $1(8.07,0.018,-0.06 \pm 0.98 i)$ and output $2(6.5088,1.4287,-0.0027,-0.0211)$. However, both output 3 $(-0.56 \pm 2.91 i,-0.0027,-0.02)$ and output $4(-0.82,-0.25$, $-0.044 \pm 0.029 i)$ can stabilize the system, specifically that output 4 has better controllability on the modes than output 3. It indicates that $\dot{\theta}$ is also the key parameter for microtab control in divergence instability case, and, more importantly, $\dot{\theta}$ overweighs $\theta$ on the control performance, corresponding to the stable feedback system with output 3 .

5.1.3. Compare Flutter Instability and Divergence Instability Cases. Compare the results of flutter instability case with divergence instability case; it reveals that (1), for both cases, the output of $h$ and the output of $\theta$ are incapable of controlling the blade vibration via the microtab, and the output of $\dot{\theta}$ has the ability of suppressing the vibration modes; (2) the difference of the results of case 1 (flutter instability) and case 2 (divergence instability) lies in the effect of output 3: for case 2 , the feedback system with output 3 can eliminate the system instability while this is not the case for output 3 on case 1. In order to investigate this phenomenon, the eigenvectors of the system with output 3 for both cases are shown in Table 4. It indicates that, for flutter instability (case 1), the coupling of flapwise mode $(\bar{h})$ and torsional mode $(\dot{\theta})$ is much weaker than that of divergence instability (case 2 ), so that the flapwise deflection is reluctant to be suppressed by the control of $\dot{\theta}$, which is the most effective signal in the vibration control; (3) although the feedback systems with output 4 can 
TABLE 4: Eigenvectors of the feedback system with output 3 for case 1 and case 2.

\begin{tabular}{ccccc}
\hline & \multicolumn{2}{c}{ Output 3 in case 1 } & \multicolumn{2}{c}{ Output 3 in case 2 } \\
& Flapwise mode & Torsional mode & Flapwise mode & Torsional mode \\
\hline $\bar{h}$ & -1.0000 & $-0.0134+0.0031 i$ & 0.9998 & $0.0789-0.0350 i$ \\
$\theta$ & $-0.0013+0.0022 i$ & 0.8926 & -0.0005 & $-0.0569-0.2942 i$ \\
$\dot{\bar{h}}$ & $-0.0013-0.0076 i$ & $-0.0004-0.0046 i$ & -0.0211 & $0.0576+0.2493 i$ \\
$\dot{\theta}$ & $-0.0000-0.0000 i$ & $-0.0450+0.2994 i$ & 0.0000 & 0.8883 \\
\hline
\end{tabular}

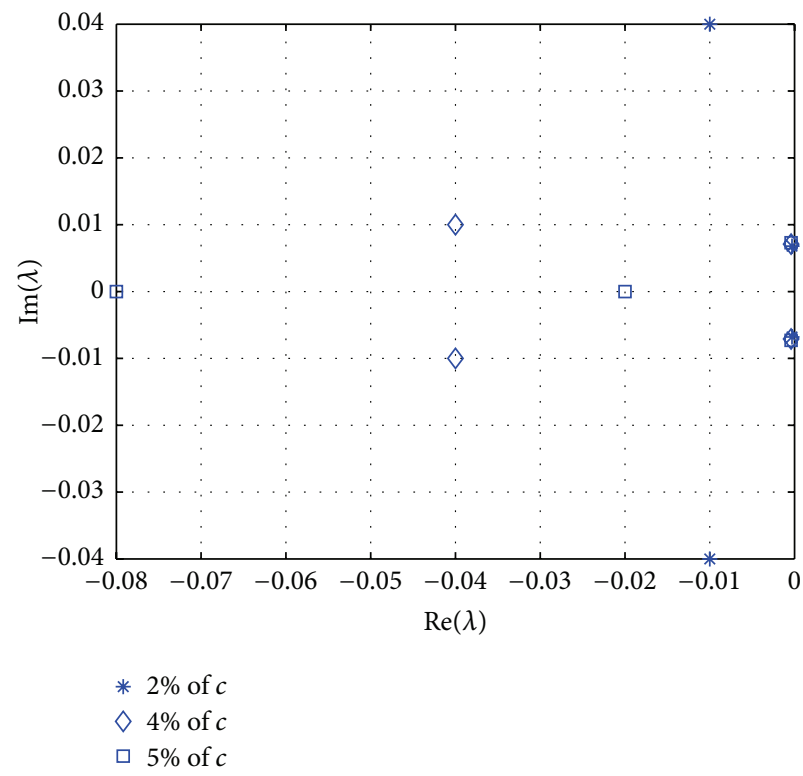

(a)

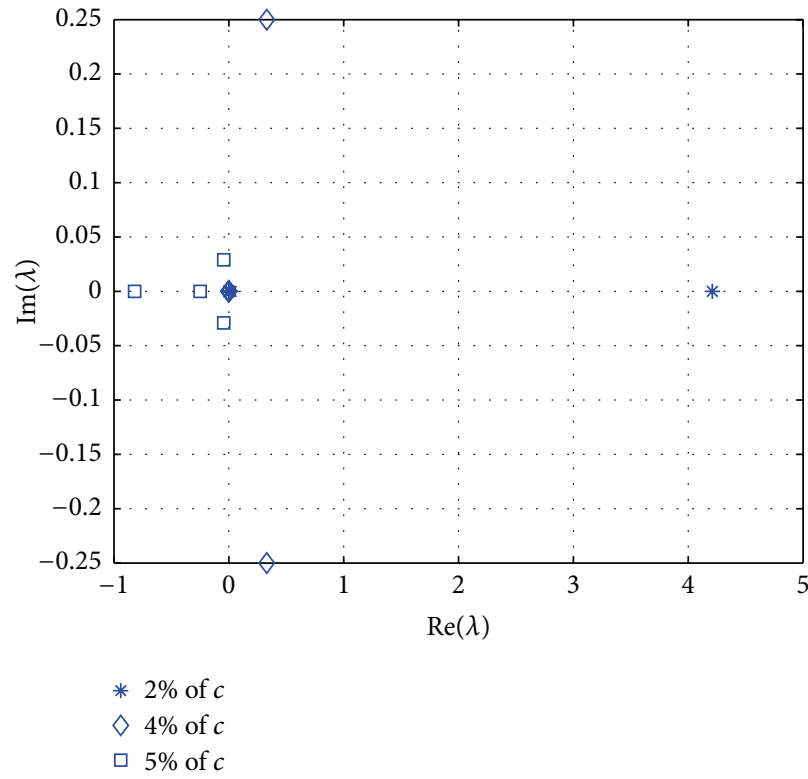

(b)

FIGURE 4: Eigenvalues of the vibration modes with different microtab deployments and output 4 for (a) flutter instability case and (b) divergence instability case.

be stabilized for both cases, the divergence instability system in case $2\left(G_{e}=-200\right)$ needs more control gain than the flutter instability system in case $1\left(G_{e}=-2\right)$, which shows that divergence instability is more difficult to control than the flutter instability. Note that $G_{e}=-2$ is already good enough to stabilize the system in flutter instability case while it lacks the control ability for the divergence instability case, which needs more power from the controller.

5.2. Control Input of Microtab Actuation. Since the feedback aeroelastic system is chosen with the appropriate output of $\dot{\theta}$, the limitation of the microtab deployment needs to be considered for practice (normally $2 \%$ of $c-5 \%$ of $c, c$ is the chord length of the airfoil section). In this section, three different deployments of the microtab are tested to verify the control capability of the microtab on flutter instability and divergence instability cases. The system is taken as $\dot{q}=$ $A q+B_{i} u, u=G_{e} y, i=1,2,3$ with the output $y=\dot{\theta} . B_{1}, B_{2}, B_{3}$ are corresponding to the different microtab deployment $(2 \%$ of $c, 4 \%$ of $c$, and $5 \%$ of $c$ ).

The flutter instability feedback system is with the control gain $G_{e}=-2$ and $U=16 \mathrm{~m} / \mathrm{s}$; the divergence instability feedback system is with the control gain $G_{e}=-200$ and
$U=24 \mathrm{~m} / \mathrm{s}$. The eigenvalues of those two systems with different deployment of microtab are shown in Figure 4. For the divergence instability system, the instability has been improved with the increased microtab deployment. Until the full deployment of $5 \%$ of $c$, the microtab has the full controllability on vibration modes. For the flutter instability system, $2 \%$ of $c$ is good enough to suppress the vibration modes. It indicates that the small microtab deployment can have good applicability on the flutter instability control while divergence instability system needs full deployment actuation of the microtab. However, the microtab performs better on the divergence instability system than the flutter instability system with the full deployment of $5 \%$ of $c$, corresponding to the increased mode damping.

5.3. Control Effect of the Microtab. As indicated in Figures 5 and 6 , the microtab control has a good performance on the suppression of both the flutter instability and divergence instability of the airfoil section in a short time. Specifically, for flutter instability case, the oscillation of plunge displacement and torsional deflection can be mostly suppressed in $3 \mathrm{sec}-$ onds and in 4 seconds separately. For divergence instability case, it takes around 4.5 seconds to control the undamped 

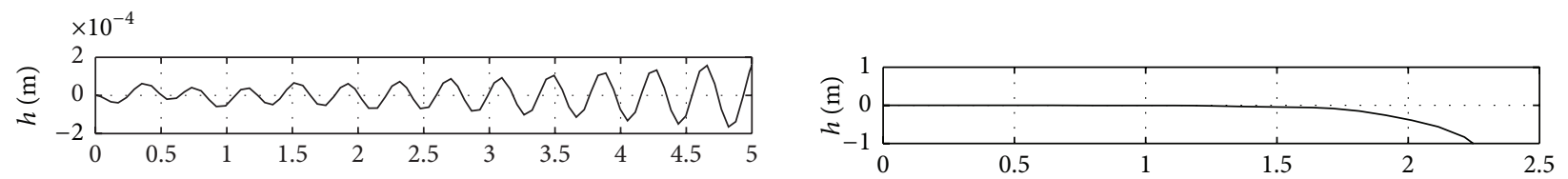

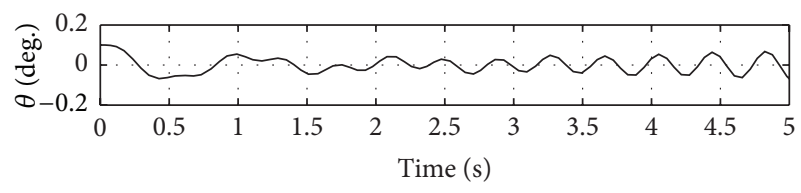

(a)

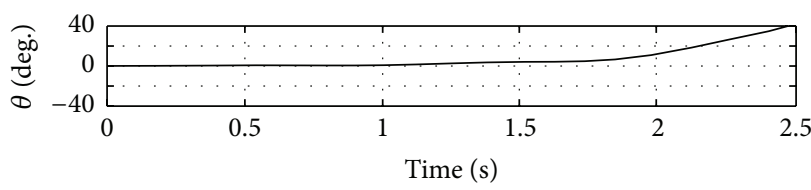

(b)

FIGURE 5: Responses of plunge displacement and torsional deflection without control for (a) flutter instability case or (b) divergence instability case.
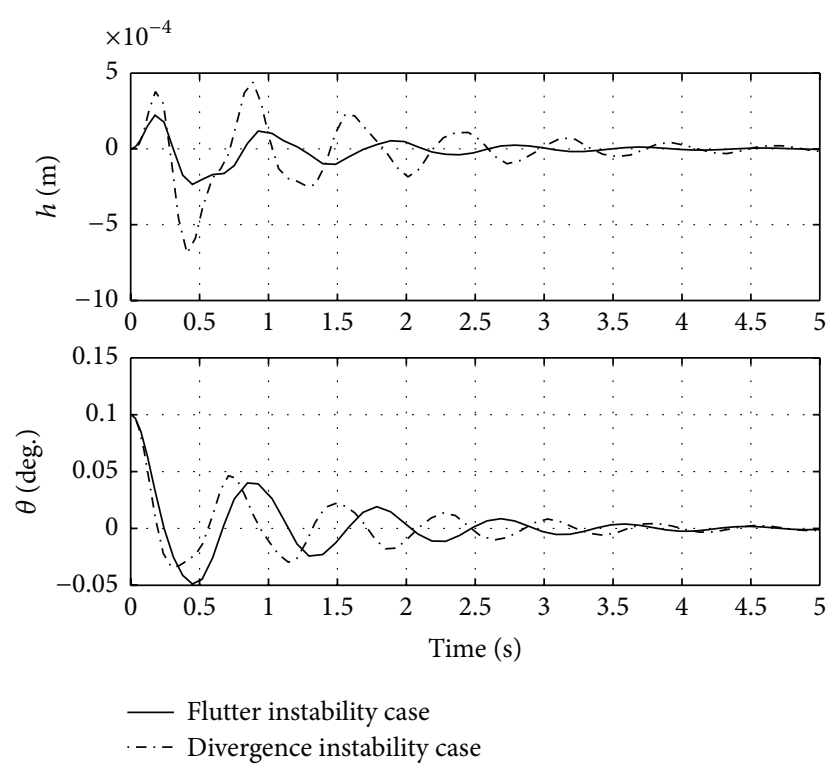

FIGURE 6: Responses of plunge displacement and torsional deflection with microtab control for flutter instability and divergence instability cases.

instability of the aeroelastic system, which also reveals that it is a little harder to stabilize the divergence instability than the flutter instability.

\section{Conclusion}

A method for developing the aeroelastic model of the smart blade section with the microtab actuator has been presented considering flapwise and torsional modes, aerodynamic forces, and microtab deployment effects. This method allows for the incorporation of the aerodynamic model approximated to the Theodorsen theory and the aerodynamic effects of the microtab into a smart blade vibration model. This model is consistent with the known aeroelastic effects of a high-order blade section mode, and it is appropriate to study controller development via the microtab actuation for passive vibration control of the smart blade section in classic flutter.
Different output feedback controllers have been investigated, and the controller using the system output of derivative of torsional deflection is confirmed as the most effective controller for passive vibration control via microtab. The control ability of the microtab is also analyzed with different actuation deployments on both flutter and divergence instability cases, indicating that flutter instability control needs less microtab deployment than divergence instability control. The simulation results of the microtab control reveal that both the instability cases can be suppressed successfully in a short time of less than 5 seconds. And it needs a little more time to control the divergence instability than the flutter instability.

\section{Conflict of Interests}

The authors declare that there is no conflict of interests regarding the publication of this paper.

\section{Acknowledgments}

The authors acknowledge support of this work through Grant 14KJB480006 from the Natural Science Foundation of the Colleges and Universities in Jiangsu Province, Grant 2014CXJ028 from School Innovation Fund of Yangzhou University, and Grant DESC0001261 from the Department of Energy, USA. The project is also sponsored by the Scientific Research Foundation for the Returned Overseas Chinese Scholars, State Education Ministry.

\section{References}

[1] M. O. L. Hansen, J. N. Sørensen, S. Voutsinas, N. Sørensen, and H. A. Madsen, "State of the art in wind turbine aerodynamics and aeroelasticity," Progress in Aerospace Sciences, vol. 42, no. 4, pp. 285-330, 2006.

[2] D. W. Lobitz, "Parameter sensitivities affecting the flutter speed of a MW-sized blade," Journal of Solar Energy Engineering, vol. 127, no. 4, pp. 538-543, 2005.

[3] A. Staino and B. Basu, "Dynamics and control of vibrations in wind turbines with variable rotor speed," Engineering Structures, vol. 56, pp. 58-67, 2013.

[4] L. Librescu and P. Marzocca, "Advances in the linear/nonlinear control of aeroelastic structural systems," Acta Mechanica, vol. 178, no. 3-4, pp. 147-186, 2005. 
[5] D. W. Lobitz, "Flutter speed predictions for MW-Sized wind turbine blades," Wind Energy, vol. 7, no. 3, pp. 211-224, 2004.

[6] D. G. Wilson, D. E. Berg, M. F. Barone, J. C. Berg, B. R. Resor, and D. W. Lobitz, "Active aerodynamic blade control design for load reduction on large wind turbines," in Proceedings of the European Wind Energy Conference, Marseille, France, 2009.

[7] M. D. Conner, D. M. Tang, E. H. Dowell, and L. N. Virgin, "Nonlinear behavior of a typical airfoil section with control surface freeplay: a numerical and experimental study," Journal of Fluids and Structures, vol. 11, no. 1, pp. 89-109, 1997.

[8] D. T. Yen, C. P. Van Dam, F. Bräeuchle, R. L. Smith, and S. D. Collins, "Active load control and lift enhancement using MEM translational tabs," in Proceedings of the Fluids Conference and Exhibit, AIAA Paper 2000-2422, Denver, Colo, USA, 2000.

[9] C. P. Van Dam, D. Yen Nakafuji, C. Bauer, D. Chao, and K. Standish, "Computational design and analysis of a microtab based aerodynamic loads control system for lifting surfaces," in MEMS Components and Applications for Industry, Automobiles, Aerospace, and Communication II, vol. 4981 of Proceedings of SPIE, pp. 25-31, San Jose, Calif, USA, 2002.

[10] P. Baek, M. Gaunaa, N. N. Sørensen, and P. Fuglsang, "Comparative study of distributed active load control concepts for wind turbine blades," in Science of Making Torque from Wind, pp. 611617, European Academy of Wind Energy, 2010.

[11] D. G. Wilson, D. E. Berg, D. W. Lobitz, and J. R. Zayas, “Optimized active aerodynamic blade control for load alleviation on large wind turbines," in Proceedings of the AWEA Wind Power Conference \& Exhibition, pp. 1-4, Houston, Tex, USA, 2008.

[12] J. P. Baker, K. J. Standish, and C. P. van Dam, "Two-dimensional wind tunnel and computational investigation of a microtab modified airfoil," Journal of Aircraft, vol. 44, no. 2, pp. 563-572, 2007.

[13] D. T. Y. Nakafuji, C. P. van Dam, R. L. Smith, and S. D. Collins, "Active load control for airfoils using microtabs," Journal of Solar Energy Engineering, Transactions of the ASME, vol.123, no. 4, pp. 282-289, 2001.

[14] M. D. Maughmer and G. Bramesfeld, "Experimental investigation of gurney flaps," Journal of Aircraft, vol. 45, no. 6, pp. 20622067, 2008.

[15] K. J. Standish, Aerodynamic analysis of blunt trailing edge airfoils \& a microtab-based load control system, University of California, Davis, Calif, USA, 2003.

[16] K. J. Standish and C. P. van Dam, "Computational analysis of a microtab-based aerodynamic load control system for rotor blades," Journal of the American Helicopter Society, vol. 50, no. 3, pp. 249-258, 2005.

[17] T. Theodorsen, "General theory of aerodynamic instability and the mechanism of flutter," NACA Report 496, 1935.

[18] P. P. Friedmann, "Recent trends in rotary-wing aeroelasticity," Vertica, vol. 11, no. 1-2, pp. 139-170, 1987.

[19] B. G. Van der Wall and J. G. Leishman, "On the influence of time-varying flow velocity on unsteady aerodynamics," Journal of the American Helicopter Society, vol. 39, no. 4, pp. 25-36, 1994.

[20] B. S. Kallesøe, "A low-order model for analysing effects of blade fatigue load control," Wind Energy, vol. 9, no. 5, pp. 421-436, 2006.

[21] T. Liu, Y. Ren, and X. Yang, "Nonlinear aeroelastic stability analysis of wind turbine blade with bending-bending-twist coupling," Journal of Fluids and Structures, vol. 42, pp. 488-502, 2013.
[22] J. W. Larsen and S. R. K. Nielsen, "Non-linear dynamics of wind turbine wings," International Journal of Non-Linear Mechanics, vol. 41, no. 5, pp. 629-643, 2006.

[23] J. W. Larsen and S. R. K. Nielsen, "Nonlinear parametric instability of wind turbine wings," Journal of Sound and Vibration, vol. 299, no. 1-2, pp. 64-82, 2007.

[24] J. W. Larsen, R. Iwankiewicz, and S. R. K. Nielsen, "Nonlinear stochastic stability analysis of wind turbine wings by Monte Carlo simulations," Probabilistic Engineering Mechanics, vol. 22, no. 2, pp. 181-193, 2007.

[25] B. S. Kallesøe, "Equations of motion for a rotor blade, including gravity, pitch action and rotor speed variations," Wind Energy, vol. 10, no. 3, pp. 209-230, 2007.

[26] G. Platanitis and T. W. Strganac, "Control of a nonlinear wing section using leading- and trailing-edge surfaces," Journal of Guidance, Control, and Dynamics, vol. 27, no. 1, pp. 52-58, 2004.

[27] K. Ogata, Modern Control Engineering, Prentice Hall, New York, NY, USA, 5th edition, 2009. 

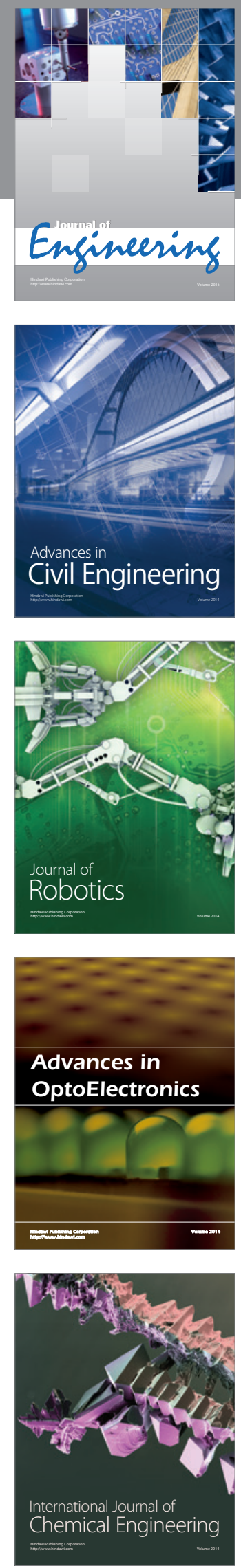

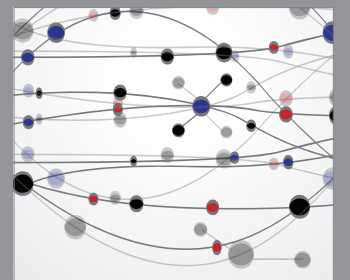

The Scientific World Journal
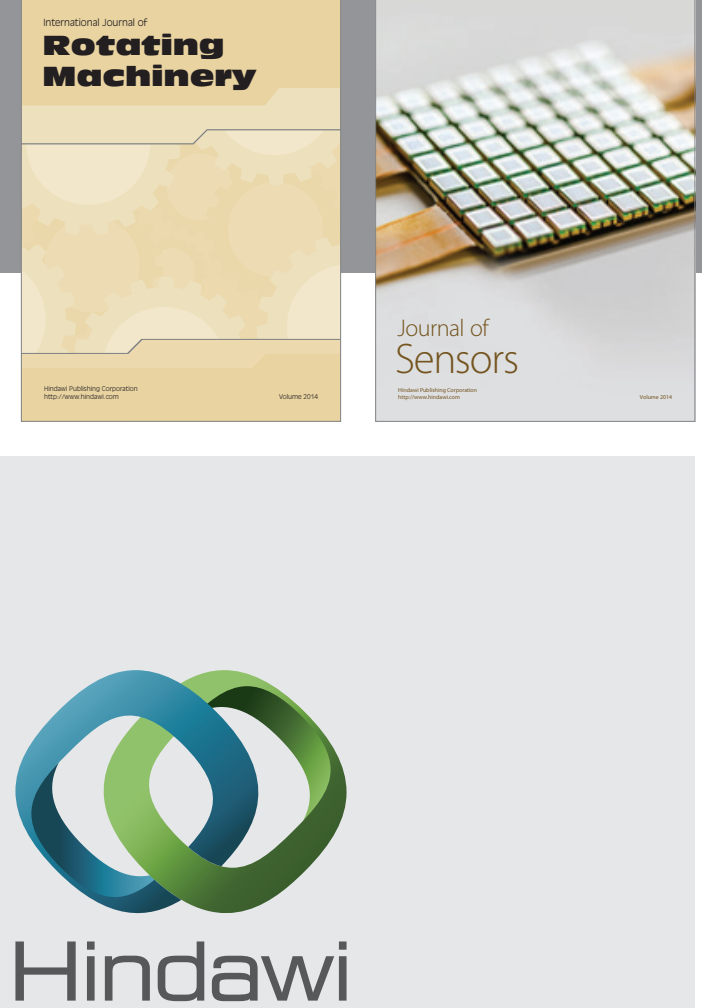

Submit your manuscripts at http://www.hindawi.com
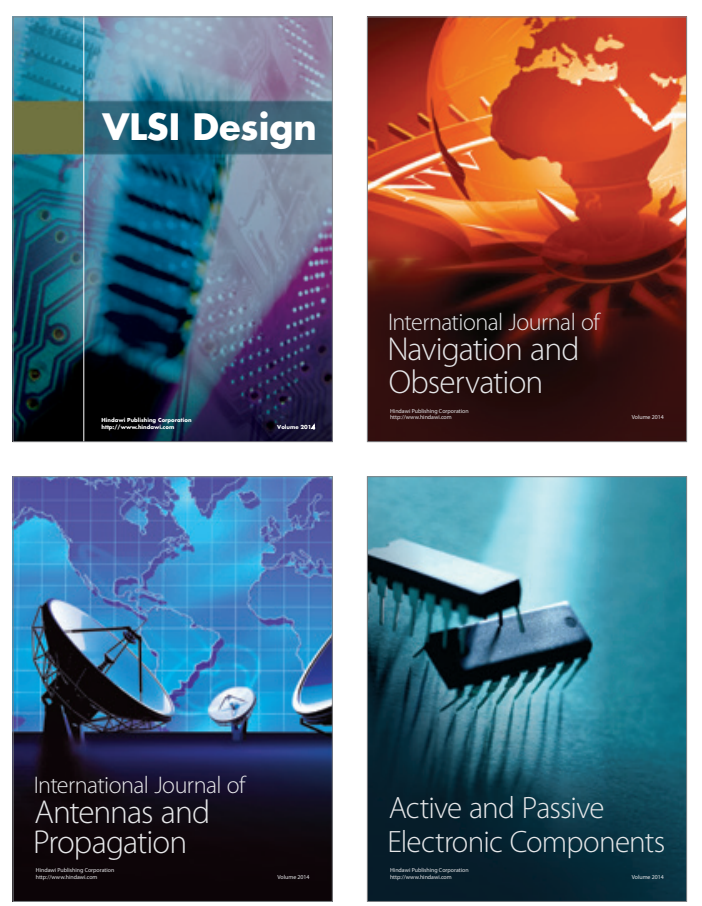
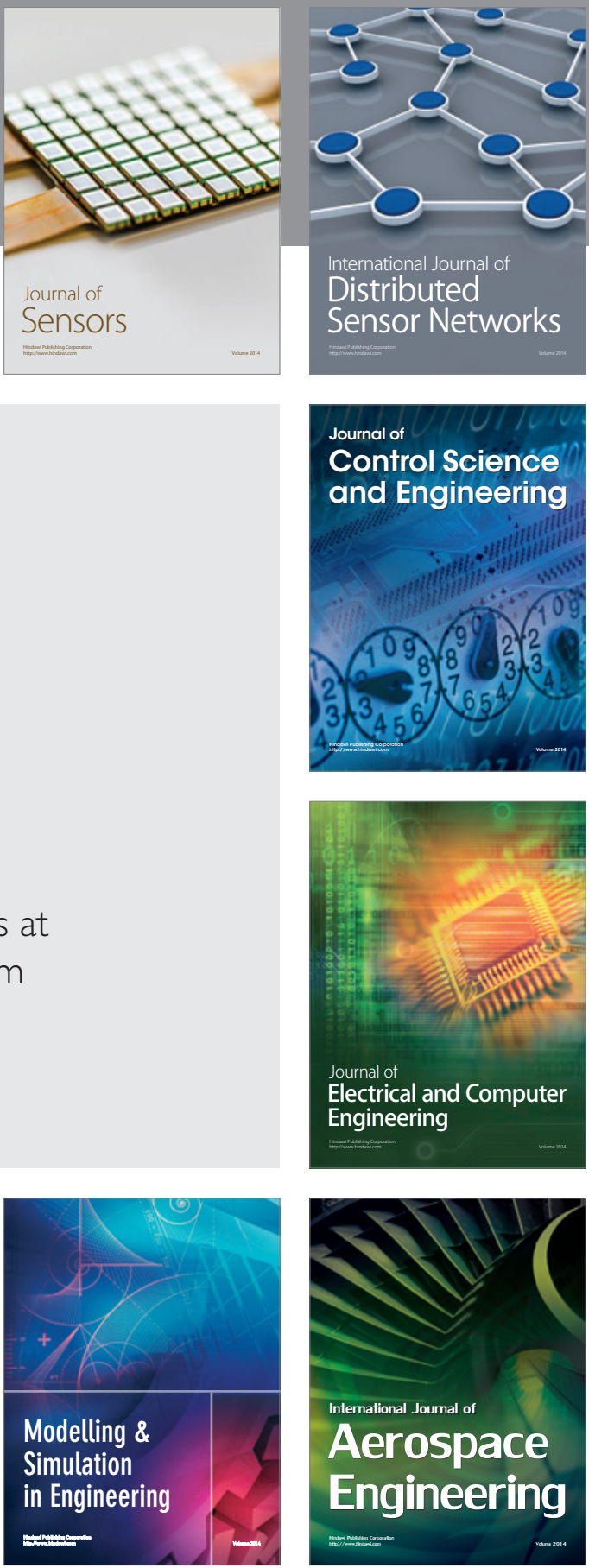

Journal of

Control Science

and Engineering
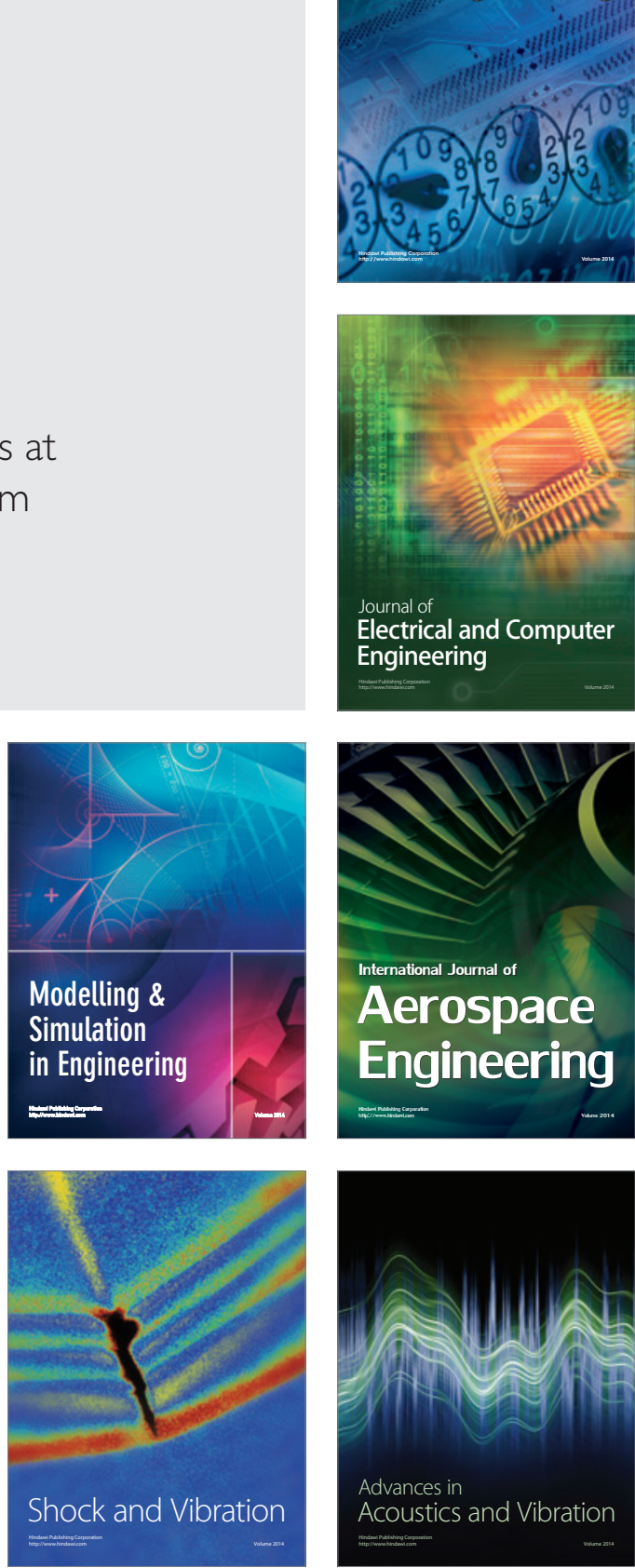